\title{
OS SONS E A EMBRIAGUEZ NA TRAGÉDIA SEGUNDO NIETZSCHE
}

\author{
GUSTAVO RUIZ DA SILVA ${ }^{1}$ \\ IAN ALANKULE PURVES ${ }^{2}$
}

\begin{abstract}
Resumo: O presente artigo tratará, no pensamento de Nietzsche, do cotejo entre a concepção de expressão musical e a noção de esquecimento de si. O filósofo, assim, a elabora a partir de uma interpretação peculiar da tragédia grega, da qual absorve as alegorias de Apolo e Dionísio, e finda por relacionar a música com sua concepção mais ampla de arte. Além disso, o artigo tece relaçôes entre a mencionada formulação de Nietzsche, as concepções de Gênio Criador em Schopenhauer e de Obra de Arte Total em Wagner.
\end{abstract}

Palavras-chave: Nietzsche; Arte; Tragédia; Schopenhauer; Wagner.

O Nascimento da Tragédia é a primeira obra publicada por Friedrich Nietzsche, datada de janeiro de 1872. No fervilhar intelectual dessa época na Alemanha se discutia a produção de uma identidade cultural que pudesse propulsionar o processo de Unificação Alemã que, até então, se figurava como uma confederação demasiada fragmentária (MACHADO, 2006, pp. 5-7). Em tal obra o filósofo busca uma interpretação alegórica no estudo da tragédia grega clássica ${ }^{3}$, sob a ótica da força desta de ter produzido uma unidade propriamente helênica. Traria também, e ao encontro deste tipo artístico, a obra de Richard Wagner como o ele-

1 Graduando em Ciências Sociais pela Pontifícia Universidade Católica de São Paulo (PUC-SP) e em Filosofia pela Universidade de São Paulo (USP). Atualmente faz parte do "Grupo de Pesquisa Michel Foucault CNPq/PUC-SP” e do projeto de pesquisa “Imagem, Imaginação e Imagem de Si”, ambos do Programa de PósGraduação em Filosofia da PUC-SP.

ruizdasilva.gustavo@usp.br

2 Graduando em Filosofia pela Universidade de São Paulo. Atualmente pesquisa a obra de Georges Can guilhem.

10765962@usp.br

3 Exterior ao escopo temático desse artigo permanece a indicação de que embora F. Nietzsche tenha se destacado como pensador do trágico, não fora ele o primeiro a realizar este retorno ao contexto estético grego. Isto se engloba em um mais amplo movimento de "nostalgia da Grécia”, caro ao Classicismo Alemão - como salienta ainda R. Machado (2006) —, que propunha um retorno ao ideal estético dos gregos do século V a. C. 
mento cultural disponível na Alemanha com suficiente força e adequação a servir de foco simbólico de todo este processo ${ }^{4}$.

Os dois polos, deveras distantes entre si, restam nitidamente atados conforme se avança no objetivo do filósofo em elaborar tal conjugação. Há na tragédia grega e na ópera wagneriana uma potência inebriante capaz de deslocar radicalmente a posição de indivíduos, de um povo, de modo que pela interpretação de Nietzsche o caso grego se torna exemplo da conformação de um sentido de unidade no povo helênico. Assim, o autor observava no entrelaçamento cultural popular expresso na literatura alemã com as questões germânicas, dadas as bases nas lendas e mitos, o renascimento cultural do país no drama musical wagneriano. A música, segundo Nietzsche (GT/NT 5, §2-3, 2008, p. 44), alcançava a conciliação dos elementos dionisíacos e apolíneos; e Wagner, para ele, o único capaz de resgatar na tragédia essa máxi$\mathrm{ma}^{5}$, e uni-la à obra de arte total (Gesamtkunstwerk) wagneriana ${ }^{6}$.

Era aí que versaria a revitalização do mito enquanto sustentáculo cultural ${ }^{7}-$ tal como ele defendia haver ocorrido analogamente na Grécia arcaica - e na abertura para a cria ção da semântica da obra de arte por meio, não da elaboração abstrata, mas da intuição do es pectador. Deste modo, é preciso analisar minuciosamente como a tragédia grega produz tal efeito, como a ópera é capaz de afetar o povo alemão, e como se torna possível uma tradução contextual de tamanho fôlego e astúcia.

É com isto que não somente o aspecto técnico de ambas produções artísticas, bem como suas concepções, são requisitos para compreender o procedimento elaborado pelo filósofo, mas também a historicidade do desenvolvimento das duas vertentes aproximadas. As-

$4 \quad$ A noção de identidade alemã se baseava na ideia do império, na cultura alemã e na língua alemã, como menciona Norbert Elias em O Processo Civilizador (1995). Mas, em questões de demarcação de território, a Alemanha era fraca e não tinha em sua constituição um território único.

5 Segundo Barrenechea (2001), o retorno do trágico é a resposta ao que Nietzsche chama de "história de um erro", período em que o pensamento metafísico dominou o pensamento ocidental, mas que se esgotou, pos sibilitando um retorno glorioso do homem às suas potências vitais originárias expresso pela fórmula Incipt Zaratustra ou Incipit Tragoedia. Desta forma, pode-se pensar que a discussão de O Nascimento da tragédia será retomada no Zaratustra, mas com uma linguagem com mais consistência e clareza.

6 Gesamtkunstwerk, ou obra de arte total, é um termo da língua alemã atribuído ao compositor alemão Richard Wagner e refere-se ao ideal wagneriano de junção das artes - música, teatro, canto, dança e artes plásticas. "Para esta junção era necessário que cada uma destas artes se colocasse a mercê de uma ideia integradora, que transpasse a própria individualidade de cada arte” (PEREIRA, 1995, p. 7).

$7 \quad$ Os mitos se pensam entre si ao mesmo tempo em que pensam a sociedade de onde provêm, mas não pertencem a uma única sociedade, pois o que é mais próprio deles é viajar por entre elas e, assim, transformaremse. 
sim, um tema tratado por Nietzsche ganha notoriedade e relaciona sua interpretação sobre o percurso vital da tragédia grega em conjunto a seus principais autores: Ésquilo, Sófocles e Eurípedes $^{8}$. O primeiro assinalado como ápice da tragédia, enquanto o último como o ponto de decadência e fim de sua grandeza. A acusação do filósofo alemão não poderia ser mais interes sante: Eurípedes corrompe a tragédia grega por excesso de socratismo - racionalização ${ }^{9}$.

Urge, então, discutir o caráter da representação artística, pois um renomado autor representou mal, ao racionalizar excessivamente, uma espécie de arte cuja potência está na radicalidade afetiva. Segundo Nietzsche (2006, pp. 28-29), a arte diz respeito à vida entendida enquanto impulso, pulsão e instinto. É através de seus eixos de expressão - poético, teatral e musical - que a tragédia produz o efeito inebriante almejado, e na visão do filósofo, dentre toda a composição técnica desta espécie de arte, o coro era claramente o ponto de inflexão deste efeito. Formado por uma poderosa massa sensível, é ele quem tem a função de representar o mais profundo conflito entre a vida e o pensar, através da lírica e da música em diálogo com os outros intérpretes do palco.

Destas consideraçóes se pode extrair uma primeira diferença entre dois modos importantes de expressão artística da tragédia grega, a saber: o musical e o poético. A partir disto, passa-se a investigar a mencionada potência inebriante desta arte pelo aspecto do modo de expressão musical, pois - em oposição ao poético, e cotejado à crítica nietzscheana a Eurípedes - resta como domínio que permite um afastamento em relação à razão através do distanciamento em relação ao logos, que guarda junto à poética, a forma simbólica da palavra.

De volta ao nascimento da tragédia, o filósofo interpreta que a força desta se deve a ter nascido no povo grego a união entre dois deuses que se caracterizavam por serem potências afirmativas: Apolo e Dionísio. O primeiro é Deus da Arte e das representações oníricas, seu elemento é a beleza; ele se apresenta junto à luz e ao Sol, e assim se torna também deus do conhecimento verdadeiro ${ }^{10}$. O segundo é o deus que representa o furor do impulso, e assim se

8 Nietzsche, a partir da percepção e do sentido que os gregos da época das tragédias davam às suas experiências, procura erguer seu discurso tomando por base o caráter imanente daquilo que o homem projeta sobre a existência.

9 O socratismo de Eurípedes consiste em sua crença de que "tudo precisa ser consciente para ser belo". Ao ser o primeiro dramaturgo trágico que seguiu uma estética da consciência, construiu personagens que eram realmente como falavam, se expressavam inteiramente (enquanto os de outros dramaturgos apenas balbuciavam sobre si), introduziu o prólogo à tragédia, e mesclou a fala cotidiana ao palco (NIETZSCHE, 2005, pp. 29-33).

10 Como dito por Machado (1999, p. 20): "O primeiro importante resultado da análise nietzschiana, ao mostrar como os gregos ultrapassaram, encobriram ou afastaram um saber que ameaçava destrui-los, graças a uma concepção apolínea da vida, é o elogio da aparência. A apologia da arte já significa, como sempre significará para 
Os sons e a embriaguez na tragédia segundo Nietzsche

apresenta junto à embriaguez e ao êxtase; representa também a reconciliação entre Natureza e Homem, esse que se esquece de si próprio, ao se associar à bebida narcótica e deixar correr o instinto primaveril - de florescimento e expansão do impulso (NIETZSCHE, 2004, pp. 11$13)$.

Os impulsos apolíneo e dionisíaco, apresentados pelo autor, não são somente modos de expressão artística do homem, mas "poderes artísticos que, sem a mediação do bomem, irrompem da própria natureza" (GT/NT, KSA 1, §30), onde ambos estados estéticos são acompanhados por fenômenos fisiológicos: pelo sonho ${ }^{11}$ e pela embriaguez ${ }^{12}{ }^{13}$. Cito:

O essencial dessa concepção é a ideia da arte em relação com a vida: a arte é entendida, tanto no sentido psicológico como em seu sentido fisiológico, como o grande estimulante, como o que nos impulsiona eternamente a viver, a viver eternamente (NACHLASS/FP 14, KSA 13, §228).

Os deuses da cosmologia grega não se mostram como qualquer tipo de obrigação ou ascese, mas como um espelho no qual projetam a si próprios, como espécie de exaltação da vida. Esta é afirmada em sua inteireza e não se esquece aqui do sofrimento em detrimento da alegria: a embriaguez dionisíaca e o conhecimento apolíneo - bem como os outros deuses olimpianos - são resultantes da sabedoria de Sileno, qual seja a de que é melhor não existir e, secundariamente, é melhor morrer logo (NIETZSCHE, 2008, pp. 32-35). Trata-se de não restar apagado ou negado o componente do sofrimento na existência, e é este caráter do povo grego que o filósofo insiste em destacar. Vale citar o dito por Nietzsche acerca dos gregos: " $A$ seus dois deuses da arte, Apolo e Dionisio, vincula-se nossa cognição de que no mundo belênico existe uma enorme contraposição, (...) até que, por fim, através de um miraculoso ato metafísico da vontade helênica, apareceram emparelhados” (GT/NT 1, KSA 1, §25).

Nietzsche, uma apologia da aparência como necessária não apenas à manutenção, mas à intensificação da vida". Conforme Dias (2011, p. 85), a aparência tem potência, ela é necessária à vida, é uma maneira de escapar da desordem do mundo.

11 Para Nietzsche, o sonho, como “origem da metafísica” (2000, p. 5), é um estado herdado dos primór dios da humanidade, quando "a alucinação era extraordinariamente frequente" (2000, p. 12). Descrito como atividade fisiológica por excelência derivada de uma excitação do corpo até a função cerebral e a consequente confusão vivida pelo espírito.

12 Como dito em "Crepúsculo dos ídolos": "para haver arte, para haver alguma atividade e contemplação estética, é indispensável uma precondição fisiológica: a embriaguez" (GC/CI, Incursóes de um extemporâneo, 8, KSA 6, \$116)

13 O processo de embriaguez rompe com o exercício da obediência; e a reiteração dos ideais de desmedida e prazer, criando um mundo à sua maneira. 
O que o interessa aqui é a capacidade de viver o sofrimento em plena potência, e transformá-lo em arte. Se Apolo está ligado aos princípios da razão, da verdade, do belo, dos limites claros e alumiados, e Dionísio pelo contrário se liga ao desaparecimento de toda e qualquer individuação (inclusa a que transforma o homem em indivíduo) através do florescimento primaveril do impulso - é a arte trágica que guarda toda esta potência. Para Nietzsche, a arte trágica é o brilhante momento em que a embriaguez do estado dionisíaco é conciliada com a possibilidade de expressão artística para fora do próprio estado de embriaguez ${ }^{14}$.

Se torna de primeira ordem, portanto, o processo de criação do artista trágico, responsável por produzir uma expressão que transfira parte da força indomável do estado dionisíaco. A reflexão nietzscheana sobre este aspecto é diretamente influenciada pelas concepções schopenhaueriana e wagneriana do gênio criador, razão pela qual a análise passa a este eixo.

Para Schopenhauer, o gênio seria caracterizado em essência pela preponderância de sua capacidade de contemplação estética das Ideias ${ }^{15}$ (SCHOPENHAUER, 2005, pp. 253254). A arte seria, adiante, a repetição representativa das Ideias eternas, ou seja, o que se pode extrair como essência dos fenômenos do mundo ${ }^{16}$. Assim, o mundo visto pelo filósofo como Vontade (essência) e Representação (fenômeno da Vontade), seria capturado pelo gênio artístico que, através do estado contemplativo de sujeito puro do conhecimento ${ }^{17}$, seria capaz de ver a essência do mundo, e representá-la artisticamente ${ }^{18}$.

Todavia, quando Schopenhauer elabora uma hierarquização das artes pela intensidade (graus de objetividade) das Ideias que cada espécie artística é capaz de atingir, tal con-

14 Apolo e Dionísio são forças antagônicas que, em nível ontológico, são independentes e agem em conflito sem serem necessariamente vinculados ao indivíduo, de modo que não são os impulsos por si só que configu ram a tragédia ática, mas a apropriação específica que o povo grego faz deles (PEREIRA, 2015, pp. 177-200).

15 São concebidas como objetividade perfeita da essência do mundo, e com a força das formas platônicas.

16 A essência do mundo para Schopenhauer (1988, p. 97) é a Vontade, concebida no sentido kantiano de coisa-em-si.

17 Tal estado é definido (SCHOPENHAUER, 2005, pp. 245-247) como o modo de consideração do mundo que ocorre fora das formas do tempo e espaço, e não se opera mais pelo princípio de causalidade - desfeitura do princípio de razão; o indivíduo desaparece na Vontade, e se torna conjuntamente a coisa-em-si indiferenciada.

18 Para Kant, do ponto de vista da consciência racional, a realidade é nossa representação, ilusão construída por nosso princípio de razão que percebe o mundo fenomenal, sob o princípio de individuação, no espaço e no tempo, e segundo a lei da causalidade. Assim, Schopenhauer sustenta uma dualidade naquilo que tange ao conhecimento do mundo já inscrito no título de sua obra maior - O mundo como vontade e representação onde se encontra uma majestosa imagem que apresenta o homem achando tranquilidade e apoio no principium 
cepção de gênio criador adquire nuances. A imediatidade, necessidade e infalibilidade de compreensão do som, por qualquer ouvinte, fazem com que a música ultrapasse o princípio de razão e representação; o filósofo concebe a música como cópia da Vontade mesma, sem intermediação das Ideias (representações da Vontade) - como ocorre nas outras artes. O gênio musical opera de maneira inteiramente diferente em relação às outras artes, pois a criação musical essencialmente não se dá por intermédio de conhecimentos técnicos ou numéricos (representações) - ela ocorre de maneira completamente afastada da reflexão e intenção da consciência. Uma queda bastante obscura e aberta à proposição, a se ver pela própria postura do filósofo que recorre mesmo ao critério de inspiração do gênio, como se demarcasse internamente um limite da apreensão verbal do processo (SCHOPENHAUER, 2005, pp. 336-342).

Wagner, desta maneira, aproveita o vão para produzir um deslocamento importante na concepção do gênio musical - e Nietzsche o absorveria em sua leitura da tragédia. Wagner adiciona a concepção da consciência de si do gênio sobre o critério schopenhaueriano da inspiração ${ }^{19}$ : uma parte da consciência direcionada às intuiçốes externas, e outra às internas, ambas somadas ao fato de que a composição musical não recorre a imagens e representações, mas sim produz o efeito de desfazer a concepção schopenhaueriana de gênio como sujeito puro do conhecimento indiferenciado da coisa-em-si; produz-se o gênio musical como indivíduo cujo contato com a essência do mundo (Vontade) se dá pela reminiscência ao mais íntimo de si, já que também é parte da natureza (WAGNER, 2010, pp. 11-12).

Não por menos o músico se vale de Beethoven como signo do gênio musical e de seu processo de perda de audição como metáfora da maturação de sua potência criadora. Ni etzsche parte já deste atrelamento do gênio criador musical a um indivíduo, e por esta razão seu artista trágico é aquele que descobre pelo impulso a essência do mundo, quando extático, e depois de retornar à vida cotidiana produz uma expressão artística capaz de abarcar o anterior estado.

Neste sentido, é preciso demarcar que o artista trágico é visto como indivíduo quando está fora do estado dionisíaco, pois o que o caracteriza é precisamente sua aptidão de se juntar à embriaguez de Dionísio (que inclui o processo de esquecimento de si, de des-indivi-

individuationis e adjudicando-se à ilusão da representação para poder viver. Em seu ponto de vista acerca da experiência interna, está-se em contato direto com a realidade tal como ela é; tem-se o conhecimento imediato da coisa em si que é a Vontade. Na contramão de seu mestre, Nietzsche mostra o artista apolíneo suportando e dignificando a vida em seu mundo fictício de beleza (CASTRO, 2008, pp. 127-142).

19 A criação artística não tem por "autor" o eu consciente de si e reconhecível por todos, mas a potência da vida em sua necessidade constante de ultrapassar a si mesma. 
duação) e, ao se equilibrar novamente com a força de Apolo, transportar tal realidade para a obra de arte (NIETZSCHE, 2008, p. 26-27) ${ }^{20}$. Esta música e lirismo ocorrem quando o artista está dissolvido no Um-primordial ${ }^{2122}$, e depois são transportados para a esfera da arte trágica. No estado dionisíaco "o homem não é mais artista, tornou-se obra de arte: a força artística de toda a natureza, para a deliciosa satisfação do Ur-Einen, revela-se aqui sob o frêmito da embriaguez" (NT, §1, KSA, I, 2008, pp. 30-31).

Anna Hartmann Cavalcanti retoma (2003, p. 209) de um texto do filósofo publicado postumamente, apesar de escrito à época de elaboração de O Nascimento da Tragédia, a concepção de que arte e vida são derivadas de uma "força inconsciente produtora de formas". A criação foi pensada por Nietzsche como a transformação gradual da visão e do sonho em imagens poéticas, o que revela o pressuposto de um inconsciente de energias e impulsos. Deste modo, tal força estaria produzindo, no artista trágico, formas e visões figuradas do homem e da natureza; bem como no estado dionisíaco, na procriação e no indivíduo ${ }^{23}$, formas e símbolos anteriores à concepção consciente (CAVALCANTI, 2003, p. 210).

A incessante produção de formas é, segundo Nietzsche, um "meio de escapar do perpétuo sofrimento da pulsão ${ }^{24 ”}$. O filósofo refere-se aqui aos dois momentos que compõe (sic) a criação: o mundo não figurativo das pulsões, daquilo que ja-

20 Na contra-mão de Schopenhauer, para quem a singular saída fornecida ao homem versa, em última instância, na negação da vontade, Nietzsche arquiteta um pessimismo outro, um pessimismo da potência, da fortitude, que conta com o encantamento da arte para transfigurar a terrível verdade (NIETZSCHE, NT/ KSA, I, Tentativa de autocrítica, 2008, p. 12-14).

21 É definido (NIETZSCHE, 2008, p. 28) como o mistério que resta após a queda do véu de Maïa - expressão schopenhaueriana para sintetizar o modo de consideração racional, realizado pelo indivíduo, e que con siste na fragmentação, emissão de individuações da realidade fenomênica.

22 Segundo o autor, "na embriaguez dionisíaca, no impetuoso percorrer de todas as escalas da alma, por ocasião das agitações narcóticas ou na pulsão de primavera, a natureza se expressa em sua força mais alta: ela torna a unir os seres isolados e deixa-os sentirem como um único (NIETZSCHE, 2006, p. 12).

23 Conforme Nascimento (2006, p. 36), Nietzsche identifica o princípio de individuação schopenhaueriano ao princípio estético apolíneo. Este princípio retrata uma justiça eterna que governa o universo e Nietzsche chega a citar uma passagem da obra O Mundo como Vontade e Representação de Schopenhauer, dizendo: "tal como, em meio ao mar enfurecido que, ilimitado em todos os quadrantes, ergue e afunda vagalhóes bramantes, um barqueiro está sentado em seu bote, confiando na frágil embarcação; da mesma maneira em meio a um mundo de tormentos, o homem individual permanece calmamente sentado, apoiado e confiante no principium individuations (princípio de individuação)” (NT \$1, p. 30).

24 O trabalho de Cavalcanti opera com a tradução de Trieb para "pulsão”, enquanto a presente dissertação se vale de outra tradução, para "impulso"; sem maior complicação de rigor, dada a proposta de investigar o modo de expressão musical. O mesmo ocorre mais tarde na opção de tradução de Ur-eine para "Uno Primordial”, por Cavalcanti, enquanto se conta aqui com "Um-primordial". 
A interpretação de Cavalcanti ilumina, assim, a região do Um-primordial em que são engendradas novas formas vitais e artísticas de dissolução do artista - que não contam com representaçóes; somente em processo gradual se distinguem e, mais gradualmente ainda, transitam de impulsos não-figurados a imagens poéticas. Eis a importância do coro, e dentro deste o sobressalto, da música na interpretação nietzscheana da tragédia, pois ela, quando imiscuída à própria Vontade (essência do Mundo), resta como a única capaz de expressar (através do som) a região não-figurada de impulsos na experiência do estado dionisíaco.

A música, em parte, é expressão, e, em parte, está misturada mesmo aos impulsos não-figurados, tornando também, desta forma, parte da regência da vitalidade que ali se apresenta. Para o autor, a música dionisíaca é a expressão direta do querer, do prazer, da dor e daquilo que há de metafísico no mundo físico. Esta música de flauta - caracterizada pela violência sonora comovente, pela torrente unitária da melodia e o mundo absolutamente incomparável da harmonia - era capaz de incitar o homem à máxima intensificação de suas capaci dades simbólicas. Com ela, a vontade (o íntimo da natureza) encontrava sua expressão corpo ral completa; na mímica, na dança e no canto cultual em honra a Dionísio, o ditirambo dionisíaco (NT, §2, p. 34. KSA, I, p. 33 apud CASTRO, 2008, pp. 127-142).

Restaria, deste modo, clara a preponderância do modo de expressão musical na arte trágica ${ }^{25}$, já que ela engendraria tanto as imagens poéticas quanto os gestos ${ }^{26}$, que estariam em uma região de transição figurativa de um corpo, onde sua imagem já se pode destacar da região do Um-primordial, e que, no entanto, pode estar ainda embriagada e imersa em impul-

25 Isto se dá ao remontar a gênese da expressão trágica neste estado extático de virtude do atleta de pentatlo, típica do dramaturgo, que deveria ser dotado produtivamente como poeta e músico, diretor do coro e ator (NIETZSCHE, 2001, p. 22). Para o autor, a poesia compreende a vida social. Ao lado da música sacralizada da canção popular houve um elemento totalmente móvel: a poesia popular de massa durante as fascinantes demoníacas dionisíacas, nas quais irrompia toda a embriaguez dos sentimentos superiores (NIETZSCHE, 2006, p. 24, $\$ 2)$.

26 Cabe aqui lembrar a predileção crítica de Nietzsche por observar os gestos hábeis das mãos dos concei tos: achar "não pouca graça em observar os truques sutis dos moralistas e pregadores da moral” (DELEUZE, 2010, p. 19). 
sos. A transição aqui se dá simbolicamente pelas imagens poéticas - a música lhes é anterior. Em O Nascimento da tragédia, Nietzsche (2008, p. 40) recorre a Schiller para explicar a lírica do poeta, cujo modo de criação ocorreria através de imagens, que não seriam o primordial do processo, atingindo o artista anteriormente sem objetos ou imagens claras e definidas, mas sim pela alma de uma certa disposição musical.

Isto é o que Cavalcanti retrata como dois momentos da criação, nos quais, antes de engendrar formas a força produtiva, são mero impulso - a música a acompanha enquanto expressão e impulso ${ }^{27}$. Esta é referida, prossegue o autor, como "o único modo de expressão artístico capaz de reproduzir imediatamente a vontade” (CAVALCANTI, 2003, p. 216). Por sua vez, as imagens poéticas são a transposição deste domínio inconsciente da experiência dio nisíaca $^{28}$, que, para além de não ser abarcável pela palavra, revela nesta, seu aspecto intrínseco: o som da qual se origina (2003, pp. 228-230).

A música é, desta forma, incumbida do processo de simbolização, de transpor o que está no estado dionisíaco para uma esfera completamente diferente. Em $A$ Visão Dionisiaca do Mundo, demarca-se que é por meio dos sons que são transmitidos os movimentos da Vontade; mais especificamente, que a harmonia do som é o símbolo da essência pura da Vontade. Assim, não se é exprimível por metáfora (palavras), e também se não simboliza apenas sentimentos (que são já metáforas), mas se simboliza o Mundo mesmo (NIETZSCHE, 2004, pp. 30-31). Adiante, a dinâmica do som seria uma representação da intensidade da Vontade, e a ritmica representaria as formas da vontade (continuidade e descontinuidade) ${ }^{29}$.

27 O gesto de criação reflete as impulsóes e a audácia, onde o frenesi e o excesso presente levam ao esgota mento o antigo, aumentando e intensificando tudo o que se exprime de modo violento, constituindo assim o tempo de desejo e metamorfose do próprio ser (CAILLOIS, 1989, pp. 127-168).

28 Segundo Caillois (1989), a festa instaura e constitui um outro mundo, uma outra forma de viver a vida naquela sociedade, sendo essencialmente de fundamento transgressor e instaurador de uma nova forma de associação lúdica em que todos se apresentam, de modo imaginativo, como iguais. O festivo corresponde a função expressiva no seu processo ritualístico, este coletivo, que faz com aqueles Homens esqueçam do mundo real. A Festa se opóe ao ritmo rotineiro, comportando as orgias do consumo, sejam de sexo ou bebidas, assim como as de expressão, mímicas eróticas, gesticulações obscenas etc.

29 Falar é antes de tudo deter o poder da palavra, o exercício do poder assegura o domínio da palavra, onde os polos mantêm relacionamentos tais que o desejo de um se realiza na conquista do outro. $\mathrm{O}$ som e a vontade estabelecem relaçóes de interdependência. 
Ficando clara a importância do coro ${ }^{30}$, a música é a expressão da dor e do antagonismo do Um-primordial, da sabedoria de Sileno. Há um tempo em que se produz música na tragédia, simbolizando o Um-primordial em todo o seu peso, mas também a constituição do povo. Isto leva Nietzsche a afirmar o valor das canções populares enquanto signo da força de povos de determinadas épocas e localidades - na embriaguez dionisíaca a natureza se exprime em sua mais alta força ao reagrupar os seres antes separados e se deixar provar como Uma (NIETZSCHE, 2004, pp. 31-32; 2008, pp. 45-52).

É salientado, portanto, pela importância atribuída à música, que a força da tragédia buscada por Nietzsche não estava na imediatidade de sua compreensão pelo público ${ }^{31}$, mas na capacidade da tragédia produzir uma emoção na vontade de um povo. A capacidade de, assim, gerar uma unidade conforme o tipo de postura perante a vida que os helenos mantinham desde a criação dos Olimpianos. Também fica explícita a razão pela qual Nietzsche aponta o socratismo de Eurípedes como o fim da tragédia grega: a predominância do discurso nas obras de Eurípedes afogava aquilo que para Nietzsche era precisamente a força deste tipo de arte. Eurípedes, em seu excesso de pré-socratismo, não percebera a tragédia em sua plenipotência, e por isto acabou por deslocá-la de seu estado de equilíbrio e conciliação entre Apolo e Dionísio.

Vale aqui lembrar e ressaltar as indicações feitas por Foucault, que mostram como o discurso dá um salto mortal entre o Hesíodo e Platão, em que a verdade se desloca nesse ín terim do ato enunciativo ritualizado, eficaz e justo, para sua forma, sentido, objeto e referência, onde, nesse período de expulsão da sofística, uma certa separação se firmou no plano discursivo, onde a fala não mais era vista como algo ligado ao exercício do poder (FOUCAULT, 2016, p. 15). Assim, a música, como espécie de gênese da expressão trágica, e como auge da potência de expressão da força desta arte, resta abafada pela nova importância atribuída ao discurso, à explicitação lógica por meio das falas em meio ao espetáculo.

Com isto, este último simbolismo é da mais alta importância ao se retomar, para o filósofo, a relação entre estas divindades (divindades ao modo grego, ressalte-se) de naturezas opostas, pois o fim da tragédia também passa a representar o declínio da helenidade. Nietzsche se envolvia, à época de $O$ Nascimento da Tragédia, num esforço de construir uma identi-

30 A noção de Uno primordial - a unidade primordial de todas as coisas, é o rompimento das barreiras que separam um ser do outro e esses do universo (SCHOPENHAUER, 2005, passim) - é para Nietzsche um ser em eterna contradição e sofrimento que encontra sua redenção na contemplação estética.

31 Alguns enunciados são para todos e para ninguém... Talvez não tenhamos ouvidos prontos para escutar grandes acontecimentos. 
dade alemã forte, revelando a interpretação do filósofo de que isto demandaria um procedimento de reversão de uma situação corrente em direção a um locus apontado como ápice: o retorno $^{32}$ à boa safra cultural da tragédia grega de Ésquilo e Sófocles. Eis o lugar que guardava para seu amigo, e músico, Wagner - àquela época ${ }^{33}$.

32 O culto de Dionísio não foi iniciado por Nietzsche, segundo o que escreve Habermas, o primeiro romantismo já havia resgatado o mito como parte de um projeto de criação de uma nova mitologia (1985, p. 137). 33 Após se conhecerem no ano de 1869, Nietzsche e Wagner começam uma amizade que perdurará até o ano de 1878, quando Nietzsche anuncia o rompimento com o compositor. 
Os sons e a embriaguez na tragédia segundo Nietzsche

\section{REFERÊNCIAS BIBLIOGRÁFICAS}

BARRENECHEA, M. A. Nietzsche: para uma nova era trágica. In: BARRENECHEA, M. A. (org.) Assim falou Nietzsche III: para uma filosofia do futuro. São Paulo: Ed. 7 letras, 2001.

CAILLOIS, R. Le sacré de transgression: Théorie de la fête. In: CAILLOIS, R. L’homme et le sacré. Paris: Gallimard, 1989, p. 127- 168.

CASTRO, C. M. A inversão da verdade: notas sobre O nascimento da tragédia. Kriterion: Revista de Filosofia, v. 49, f. 117, pp.127-142, 2008.

CAVALCANTI, A. H. Símbolo e alegoria: a gênese da concepção de linguagem em Nietzsche. 2003. Tese (Doutorado em Filosofia. Orientação de Oswaldo Giacóia Jr.) - Universidade Estadual de Campinas, Instituto de Filosofia e Ciencias Humanas, Campinas, SP. Disponível em: http://www.repositorio.unicamp.br/handle/REPOSIP/279878. Acesso em: 20 mai. 2019 .

DELEUZE, G. Nietzsche et la philosophie. Gème ed. Pari: Quadrige/ PUF - Press Universitaires de France, 2010.

DIAS, R. Nietzsche, Vida como Obra de Arte. São Paulo: Ed. Civilização Brasileira, 2011.

FOUCAULT, M. A Ordem do Discurso, aula inaugural no Collège de France, pronunciada em 2 de dezembro de 1970. São Paulo: Ed. Loyola, 26a impressão, 2016

HABERMAS, J. O discurso filosófico da modernidade: Doze liçóes. São Paulo: Martins Fontes, 2000.

MACHADO, R. Nietzsche e a Verdade. São Paulo: Paz e Terra, 1999.

MACHADO, R. O nascimento do trágico: de Schiller a Nietzsche. Rio de Janeiro: Zahar, 2006. 
NASCIMENTO, A. B. O que é a psicologia para Nietzsche?. Dissertação (Mestrado em Psicologia). Niterói, Rio de Janeiro: Universidade Federal Fluminense, Instituto de Ciências Humanas e Filosofia, 2006.

NIETZSCHE, F. Humano, Demasiado Humano. Um livro para espiritos livres. Tradução Paulo César de Souza. São Paulo: Companhia das Letras, 2000.

NIETZSCHE, F. A visão dionisiaca do mundo. Tradução Marcos Sinésio Pereira Fernandes e Maria Cristina dos Santos de Souza. São Paulo: Martins Fontes, 2005.

NIETZSCHE, F. Fragmentos póstumos. In: SOBRINHO, N. C. de M. Escritos sobre bistória. Rio de Janeiro: Ed. Puc-Rio. São Paulo: Editora Loyola. 2005.

NIETZSCHE, F. Introdução à tragédia de Sófocles. Tradução Ernani Chaves. Rio de Janeiro: Ed. Zahar, 2006.

NIETZSCHE, F. O nascimento da tragédia. Tradução de J. Guinsburg. São Paulo: Companhia de Bolso, 2008.

NIETZSCHE, F. Nietzsche contra Wagner - dossiê de um Psicólogo. Tradução Paulo César de Souza. São Paulo: Companhia das Letras, 1999.

NIETZSCHE, F. La vision dionysiaque du monde. Tradução de Lionel Duvoy. Paris: Editions Allia, 2004.

PEREIRA, C. L. J. Nietzsche e a fisiologia da arte. Cad. Nietzsche, Guarulhos/Porto Seguro, v.36 n.2, p. 177-200, 2015.

PEREIRA, M. S. Cinema e Ópera: um encontro estético com Wagner. Dissertação (Mestrado em Cinema), Instituto de Cinema, Rádio e Televisão, Escola de Comunicação e Artes - USP, 1995.

SCHOPENHAUER, A. Crítica da Filosofia Kantiana. Tradução Maria Lúcia M. Cacciola. São Paulo: Nova Cultural, 1988. (Coleção Os Pensadores) 
Os sons e a embriaguez na tragédia segundo Nietzsche

SCHOPENHAUER, A. O mundo como vontade e como representação. Tradução de Jair Barboza. São Paulo: Editora Unesp, 2005.

WAGNER, R. Beethoven. Tradução de Anna Hartmann Cavalcanti. Rio de Janeiro: Zahar, 2010 . 